\title{
Predictors of enrollment in a health protection scheme among informal sector workers in Kumasi Metropolis of Ghana
}

\author{
Dina Adei, Williams Agyemang-Duah* (10 and Anthony Acquah Mensah
}

\begin{abstract}
Objective: Informal sector workers are exposed to occupational hazards which could escalate their healthcare expenditures. Thus, enrollment in a health protection scheme among informal sector workers is useful for reducing their catastrophic healthcare expenditures. However, there is scant information on factors predicting their enrollment in the National Health Insurance Scheme (NHIS) in Ghana, a gap this quantitative study aims to fill. A sample of 350 informal sector workers was involved in a cross-sectional survey.

Results: Approximately $17 \%$ of the participants were enrolled in NHIS. Respondents who had worked between 5 and 7 years were significantly more likely to enroll in NHIS compared with those who had worked below 2 years $(\mathrm{AOR}=13.159, \mathrm{Cl} 1.135-152.596, \mathrm{p}=0.039)$. The study further found that apprentices ( $\mathrm{AOR}=0.72, \mathrm{Cl} 0.353-1.056$, $p=0.005$ ) were less likely to enroll in NHIS compared with their masters. Participants who were exposed to electrical hazards $(A O R=2.93, C l 1.56-5.10, p=0.013)$ and suffered from occupational diseases ( $A O R=2.75, C l$ 1.743-5.17, $p=0.001)$ were significantly more likely to enroll in NHIS. Also, respondents who were non-Christians were significantly less likely to enroll in NHIS compared with their respective counterparts (AOR $=0.726, \mathrm{Cl} 0.067-2.503$, $p=0.011)$. The findings are useful for increasing the NHIS enrollment rate among informal sector workers in Ghana.
\end{abstract}

Keywords: National Health Insurance Scheme, Enrollment, Informal sector workers, Kumasi Metropolis

\section{Introduction}

After independence, the Government of Ghana introduced free healthcare for its citizens [1], with the rationales of removing all forms of barriers to healthcare accessibility and utilization and, also ensuring universal health coverage [2]. Free healthcare was funded through taxes and donor support [3]. As part of the free healthcare policy, the government provided additional healthcare facilities across the country and strengthened preventive interventions such as immunization and antenatal care. In the 1980 s, however, due to the poor economic growth resulting in limited resources, the government abolished the free healthcare policy [2].

Thus, the out-of-pocket payment systems were gradually implemented in Ghana in the mid-1980s [4]. With

\footnotetext{
*Correspondence: agyemangduahwilliams@yahoo.com Department of Planning, Kwame Nkrumah University of Science
} and Technology, Kumasi, Ghana this policy, there was a total withdrawal of government subsidy with patients taking care of their healthcare expenditures. The justifications of this policy were to increase funds for providers, make fee recovery legal and restrict unnecessary utilization of healthcare [2]. However, the policy was serving as an obstacle to healthcare utilization [5]. For instance, outpatient visits reduced by $66 \%$ as a result of the implementation of the cash and carry system [2].

The National Health Insurance Scheme (NHIS) was introduced in 2004 as an alternative healthcare financing mechanism in Ghana [6]. The NHIS provides free enrollment for Social Security and National Insurance Trust (SSNIT) retirees, persons aged 70 years or older, pregnant women, children under 18 years and paupers [7]. It covers about $95 \%$ of disease burden conditions of people [8] including malaria, diarrhea, respiratory tract infections, skin diseases, hypertension, diabetes and asthma [9].

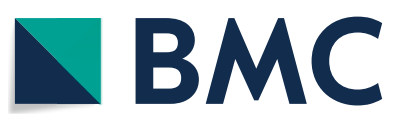

(c) The Author(s) 2019. This article is distributed under the terms of the Creative Commons Attribution 4.0 International License (http://creativecommons.org/licenses/by/4.0/), which permits unrestricted use, distribution, and reproduction in any medium, provided you give appropriate credit to the original author(s) and the source, provide a link to the Creative Commons license, and indicate if changes were made. The Creative Commons Public Domain Dedication waiver (http://creativecommons.org/ publicdomain/zero/1.0/) applies to the data made available in this article, unless otherwise stated. 
The national enrollment rates of NHIS in 2010, 2015 and 2017 were $33 \%$ ( 8.2 million), $41 \%$ (11.3 million) and $35 \%$ (10.3 million) respectively. With this, the enrollment rate of NHIS among informal sector workers in 2017 was $29.8 \%$ [6], which is below the 2017 national enrollment rate. This shows that informal sector workers have a low enrollment rate in NHIS despite their frequent exposure to occupational hazards [10] such as physical, chemical, biological [11] and other occupational injuries [12]. As such, they are likely to incur catastrophic healthcare expenditures due to their frequent exposure to occupational hazards coupled with their low NHIS enrollment. Enrollment in NHIS could help to minimize their healthcare expenditures [13]. Evidence shows that sociodemographic factors [14], such as education, gender, and income are associated with NHIS enrollment [15]. However, there is scant information on factors influencing NHIS enrollment among informal sector workers in Ghana, a gap this quantitative study aims to fill. Understanding this knowledge area would be useful for increasing the NHIS enrollment rate among informal sector workers in Ghana.

\section{Main text Methods \\ Study settings}

The study was conducted in Kumasi Metropolis of Ghana. Kumasi Metropolis represents the most populous settlement in Ghana with a population of 1,730,249 inhabitants which comprised $47.8 \%$ males and $52.2 \%$ females. About $60 \%$ of the labor force in Kumasi Metropolis predominantly engaged in informal economic activities [16].

Sample and data This study was a cross-sectional survey. A headcount of all potential participants was undertaken from September to November 2016 to determine the sampling frame because of the absence of data on the population. The headcount covered the masters and apprentices working as welders and fish processors within the study area. The headcount identified a total of 200 fish processors and ten master welders at Asafo. Meanwhile, 180 master welders were identified at Suame magazine adding up to a total of 190 welders. Slovin's sample size determination method [17], was used to determine the sample size.

$$
\mathrm{n}=\mathrm{N} /\left[1+\mathrm{N}(\alpha)^{2}\right]
$$

where, $\mathrm{n}=$ sample size; $\alpha=$ error margin of 0.05 and a confidence interval of $95 \%$, and $\mathrm{N}=$ the sampling frame. The formula was applied separately for fish processors and master welders and a sample size of 262 (129 master welders and 133 fish processors) was obtained. For every master welder selected, his senior apprentice was also selected adding up to a total of 258 welders (129 masters and 129 apprentices) and 133 fish processors yielding a total sample size of 391 participants. The fish processors had no apprentices. The response rate was $97.7 \%$ for fishmongers and $85.3 \%$ for welders, a total response rate of $91.5 \%$. Therefore, the sample size used for analyses was 350 participants comprising 220 welders and 130 fish processors. The simple random sampling was used to select the respondents because it is mostly used in health research [18]. This was operationalized by writing the numbers on pieces of paper, keeping them in a box and shuffling thoroughly. The papers were drawn one after the other until the required sample size was obtained.

Face-to-face interviewer-administered questionnaires covering information on socio-demographic, medical characteristics and enrollment in NHIS were used to elicit data from the respondents. The questions were in English but were translated to Twi (a local language of the participants) for easy understanding. This was therefore converted back to English for analyses. Written and verbal informed consents were sought from the respondents before data collection. Respondents were further assured of strict confidentiality of the information they provided.

Measures Outcome variable The outcome variable was enrollment in NHIS and was measured as a dichotomous variable indicating 'yes $=1$ ' or ' $n o=0$ '.

Predictor variables The independent variables were type of enterprise $(1=$ welding, $2=$ fish processing), type of respondents $(1=$ master, $2=$ apprentices, 3 =employee $)$, gender $(1=$ male, $2=$ female $)$, age (years) $(1=49$ or below $2=50$ or above), education $(1=$ no formal education, $2=$ basic, $3=$ secondary, $4=$ tertiary $)$, marital status $(1=$ married, $2=$ single $)$, religion ( $1=$ Christians, $2=$ non-Christians), work experience (years) $(1=$ below $2,2=2-4,3=5-7,4=8-10$, $5=11-13, \quad 6=$ above 13$)$, income $(1=\mathrm{GH} 4<1000$, $2=1000$ or above). Membership of workers association, exposure to welding light, biological hazards, electrical hazards, fire hazards, occupational injury and occupational diseases were measured as 'yes $=1$ ' or 'no $=0$ '.

Analytical framework Data were entered into a database and analyzed statistically using Statistical Package for Social Sciences (SPSS) software (version 16.0). Percentages and frequencies were used to interpret the sample characteristics of the respondents. Chi-square and Fisher exact tests were used to estimate differences between independent variables and NHIS enrollment. Simple and multiple regression models were used to estimate the 
association between independent variables and enrollment in NHIS. Based on Gujarati and Porter [19], the multiple regression model was developed as follows.

$$
\begin{aligned}
\mathrm{P}= & \alpha_{0}+\alpha_{1} \mathrm{TOR}+\alpha_{2} \mathrm{R}+\alpha_{3} \mathrm{MS}+\alpha_{4} \mathrm{WE} \\
& +\alpha_{5} \mathrm{MOA}+\alpha_{6} \mathrm{EEH}+\alpha_{7} \mathrm{OD}+\epsilon
\end{aligned}
$$

$\mathrm{P}=$ probability of enrolling in NHIS. TOR, R, MS, WE, MOA, EEH, and OD refer to the type of respondents, religion, marital status, work experience, membership of workers association, exposure to electrical hazards and occupational diseases, respectively. Also, $\alpha=$ parameters to be estimated; $\varepsilon=$ error term. Due to the use of multiple regression, we were compelled to choose different independent variables. The test results were considered significant at a probability value of 0.05 or less.

\section{Results}

\section{Sample characteristics of the respondents}

About $63 \%$ of the respondents were welders. Approximately $41 \%$ were master welders. It was revealed that $62.9 \%$ were males. Also, $34.6 \%$ were aged 49 years or below, $48.3 \%$ had a secondary level of education and $55.1 \%$ were married. Approximately 32\% had worked for more than 13 years and $92 \%$ received a monthly income of less than GH\$1000.00 (\$1 was equivalent to GH\$4.4 as of the time of the survey). Approximately $17 \%$ were members of workers association, 99\% were exposed to biological hazards, 64\% were exposed to welding light, $62 \%$ were exposed to electrical hazards and $99 \%$ were exposed to fire hazards. About 39\% were exposed to occupational injuries in 2016. Further, 61\% had suffered from occupational diseases in 2016. The study revealed a statistically significant difference between type of respondent $(\mathrm{p}=0.027)$, marital status $(\mathrm{p}=0.037)$, religion $(p=0.010)$, work experience $(p=0.003)$, membership of workers association $(\mathrm{p}=0.003)$, exposure to electrical hazards $(\mathrm{p}=0.049)$ and suffering from occupational diseases in $2016(p=0.001)$ in relation to NHIS enrollment (see Table 1).

\section{Enrollment rate of NHIS}

The result indicated that $17.4 \%$ of the respondents had enrolled in NHIS. This suggests a low enrollment in NHIS among the participants (see Fig. 1).

\section{Factors associated with enrollment in NHIS}

The variables that showed a statistically significant difference with NHIS enrollment in the Chi-square and Fisher exact test analyses were further subjected to simple and multiple regression models with the rationale of estimating their likelihood of influencing NHIS enrollment. In a simple regression model, the study found that apprentices were 0.676 times significantly less likely to enroll in NHIS compared with their masters $(\mathrm{OR}=0.676$, CI $0.284-0.576, p=0.009)$. Non-Christian participants were 0.922 times significantly less likely to enroll in NHIS $(\mathrm{OR}=0.922, \quad \mathrm{CI} 0.451-2.513, \mathrm{p}=0.003)$. Participants who had worked between 5 and 7 years were 5.4 times significantly more likely to enroll in NHIS $(\mathrm{OR}=5.400$, CI 1.442-20.226, $\mathrm{p}=0.012$ ). Respondents who were members of workers association were 2.509 times significantly more likely to enroll in NHIS $(\mathrm{AOR}=2.509, \mathrm{CI}$ $1.364-4.618, p=0.03$ ). Those who were exposed to electrical hazards were 1.8 times significantly more likely to enroll in NHIS $(\mathrm{OR}=1.8$, CI 1.102-3.05, $\mathrm{p}=0.045)$. Participants who had suffered from occupational diseases were 2.2 times significantly more likely to enroll in NHIS $(\mathrm{OR}=2.2$, CI 1.25-4.256, $\mathrm{p}=0.001)$.

In a multiple regression analysis, we found that apprentices were 0.72 times significantly less likely to enroll in NHIS than their masters $(\mathrm{AOR}=0.72$, CI $0.353-1.056$, $\mathrm{p}=0.005)$. Non-Christians were 0.726 times significantly less likely to enroll in NHIS (AOR $=0.726$, CI $0.067-$ 2.503, $\mathrm{p}=0.011$ ) Respondents who had worked between 5 and 7 years were 13.159 times significantly more likely to enroll in NHIS than their respective counterparts $(\mathrm{OR}=13.159$, CI 1.135-152.596, $\mathrm{p}=0.039)$. Participants who were exposed to electrical hazards were 2.93 times significantly more likely to enroll in NHIS $(\mathrm{OR}=2.93$, CI 1.56-5.10, $\mathrm{p}=0.013$ ). Respondents who had suffered from occupational diseases were 2.75 times significantly more likely to enroll in NHIS (OR $=2.75$, CI $1.743-5.17$, $\mathrm{p}=0.001$ ) (see Table 2).

\section{Discussion}

Being one of the first studies in Ghana, this study examined factors influencing NHIS enrollment among informal sector workers in Metropolitan Kumasi. We found that $17.4 \%$ of the participants had enrolled in NHIS which is similar to a Namibian study that reported a $17.5 \%$ coverage rate of NHIS [15]. It is also similar to a $17.4 \%$ coverage rate among Ghanaian female migrants [13] but lower than 35\% national enrollment rate in 2017 [6]. The low enrollment rate could be attributed to poor quality of services offered to the insured and failure of the National Health Insurance Authority (NHIA) to intensify education on NHIS. The NHIA should, therefore, engage health insurance stakeholders to develop and implement activities to enforce compulsory enrollment to move the scheme towards universal coverage [20].

In this study, apprentices were significantly less likely to enroll in NHIS. The reason is that master welders are more likely to be wealthier than their apprentices and thus are more likely to enroll in the scheme [21]. Also, apprentices may either find it difficult getting money to pay for their enrollment fee or are unable to make time 
Table 1 Socio-demographic and medical characteristics of the respondents by NHIS enrollment

\begin{tabular}{|c|c|c|c|c|c|c|c|c|}
\hline \multirow[t]{3}{*}{ Variable } & \multirow[t]{3}{*}{ Category } & \multicolumn{6}{|c|}{ Enrollment in NHIS $(n=350)$} & \multirow[t]{3}{*}{ p-value } \\
\hline & & \multicolumn{2}{|l|}{ Yes } & \multicolumn{2}{|l|}{ No } & \multicolumn{2}{|l|}{ Total } & \\
\hline & & $n=61$ & $\%(100)$ & $n=289$ & $\%$ & $N=350$ & $\%$ & \\
\hline \multirow[t]{2}{*}{ Type of enterprise } & Welding & 34 & 55.7 & 186 & 64.4 & 220 & 62.9 & 0.205 \\
\hline & Fish processing & 27 & 44.3 & 103 & 35.6 & 130 & 37.1 & \\
\hline \multirow[t]{3}{*}{ Type of respondent } & Master & 33 & 54.1 & 111 & 38.4 & 144 & 41.1 & $0.027 *$ \\
\hline & Apprentice & 11 & 18.0 & 99 & 34.3 & 110 & 31.4 & \\
\hline & Employee & 17 & 27.9 & 79 & 27.3 & 96 & 27.4 & \\
\hline \multirow[t]{2}{*}{ Gender } & Male & 34 & 55.7 & 186 & 64.4 & 220 & 62.9 & 0.205 \\
\hline & Female & 27 & 44.3 & 103 & 35.6 & 130 & 37.1 & \\
\hline \multirow[t]{2}{*}{ Age (years) } & 49 or below & 14 & 23.0 & 107 & 37.0 & 121 & 34.6 & 0.065 \\
\hline & 50 or above & 47 & 77.0 & 182 & 63.0 & 229 & 65.4 & \\
\hline \multirow[t]{4}{*}{ Educational attainment } & No formal education & 15 & 24.6 & 50 & 17.3 & 65 & 18.6 & \\
\hline & Basic education & 8 & 13.1 & 71 & 24.6 & 79 & 22.6 & 0.096 \\
\hline & Secondary education & 34 & 55.7 & 135 & 46.7 & 169 & 48.3 & \\
\hline & Tertiary & 4 & 6.6 & 33 & 11.4 & 37 & 10.6 & \\
\hline \multirow[t]{2}{*}{ Marital status } & Married & 41 & 67.2 & 152 & 52.6 & 193 & 55.1 & $0.037^{*}$ \\
\hline & Single & 20 & 32.8 & 137 & 47.4 & 157 & 44.9 & \\
\hline \multirow[t]{2}{*}{ Religion } & Christian & 53 & 86.9 & 271 & 93.8 & 324 & 92.6 & $0.010^{*}$ \\
\hline & $\begin{array}{l}\text { Non-Christian (Islam/ } \\
\text { traditionalist/no } \\
\text { religion) }\end{array}$ & 8 & 13.1 & 18 & 6.2 & 26 & 7.4 & \\
\hline \multirow[t]{6}{*}{ Work experience (years) } & Below 2 & 6 & 9.8 & 14 & 4.8 & 20 & 5.7 & \\
\hline & $2-4$ & 6 & 9.8 & 55 & 19 & 61 & 17.4 & \\
\hline & $5-7$ & 5 & 8.2 & 63 & 21.8 & 68 & 19.4 & \\
\hline & $8-10$ & 9 & 14.8 & 58 & 20.1 & 67 & 19.1 & $0.003^{*}$ \\
\hline & $11-13$ & 4 & 6.6 & 17 & 5.9 & 21 & 6.0 & \\
\hline & Above 13 & 31 & 50.8 & 82 & 28.4 & 113 & 32.3 & \\
\hline \multirow[t]{2}{*}{ Total income/allowance per month (GHC) } & $<1000$ & 54 & 88.5 & 268 & 92.7 & 322 & 92.0 & \\
\hline & 1000 or above & 7 & 11.5 & 21 & 7.3 & 28 & 8.0 & 0.198 \\
\hline \multirow[t]{2}{*}{ Membership of workers association } & Yes & 21 & 34.4 & 50 & 17.3 & 71 & 20.3 & $0.003^{*}$ \\
\hline & No & 40 & 65.6 & 239 & 82.7 & 279 & 79.7 & \\
\hline \multirow[t]{2}{*}{ Exposure to biological hazards at the work place } & Yes & 61 & 100 & 287 & 99.3 & 348 & 99.4 & 0.515 \\
\hline & No & 0 & 0.0 & 2 & 0.7 & 2 & 0.6 & \\
\hline \multirow[t]{2}{*}{ Exposure to welding light } & Yes & 32 & 52.5 & 184 & 63.7 & 216 & 61.7 & 0.102 \\
\hline & No & 29 & 47.5 & 105 & 36.3 & 134 & 38.3 & \\
\hline \multirow[t]{2}{*}{ Exposure to electrical hazards? } & Yes & 27 & 79.4 & 115 & 61.8 & 142 & 64.5 & $0.049^{*}$ \\
\hline & No & 7 & 20.6 & 71 & 38.2 & 78 & 35.5 & \\
\hline \multirow[t]{2}{*}{ Exposure to fire hazards } & Yes & 61 & 100 & 286 & 99 & 347 & 99.1 & 0.424 \\
\hline & No & 0 & 0.0 & 3 & 1.0 & 3 & 0.9 & \\
\hline \multirow{2}{*}{$\begin{array}{l}\text { Did you experience an occupational accident which led to } \\
\text { an injury in the year 2016? }\end{array}$} & Yes & 24 & 39.3 & 112 & 38.8 & 136 & 38.9 & 0.932 \\
\hline & No & 37 & 60.7 & 177 & 61.2 & 214 & 61.1 & \\
\hline \multirow[t]{2}{*}{ Did you suffer from occupational diseases in the year $2016 ?$} & Yes & 50 & 82.0 & 162 & 56.1 & 212 & 60.6 & $0.001^{*}$ \\
\hline & No & 11 & 18.0 & 127 & 43.9 & 138 & 39.4 & \\
\hline
\end{tabular}

* $p$-value is significant at 0.05 or less

out of their busy schedules to enroll in NHIS. Thus, masters should encourage their apprentices to enroll in NHIS. The study found that non-Christian participants were less likely to enroll in NHIS compared with their Christian counterparts. This result could be due to limited funds, religious-cultural beliefs, and differences 


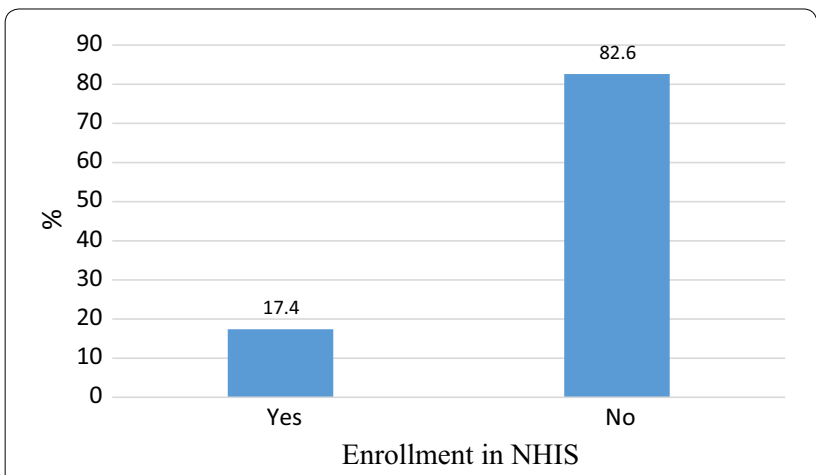

Fig. 1 Enrollment rate of NHIS among informal sector workers

in health-seeking behavior [22]. The study found that respondents who had worked for 5-7 years were more likely to enroll in NHIS than those who had worked below 2 years. This difference in the likelihood of enrollment in NHIS could be due to the differences in financial status and the number of times being exposed to occupational hazards. We further observed that respondents who were exposed to electrical hazards and experienced occupational diseases were more likely to enroll in NHIS which may be subject to their perceived poor health status $[20,23]$.

\section{Conclusion}

This study examined factors predicting NHIS enrollment among informal sector workers in Kumasi Metropolis of Ghana. The study found a low enrollment rate in NHIS among informal sector workers. Respondents who had worked between 5 and 7 years were significantly more likely to enroll in NHIS. Also, apprentices were less likely to enroll in NHIS. Participants who were exposed to electrical hazards and occupational diseases were more likely

Table 2 Factors associated with enrollment in NHIS among informal sector workers

\begin{tabular}{|c|c|c|c|c|}
\hline Variables & $\begin{array}{l}\text { Simple regression model } \\
\text { OR }(95 \% \mathrm{Cl})\end{array}$ & p-value & $\begin{array}{l}\text { Multiple regression model } \\
\text { AOR }(95 \% \mathrm{Cl})\end{array}$ & $\mathrm{p}$-value \\
\hline \multicolumn{5}{|l|}{ Type of respondent } \\
\hline Master (ref) & 1.00 & & 1.00 & \\
\hline Apprentice & $0.676(0.284-0.576)^{*}$ & $0.009^{*}$ & $0.72(0.353-1.056)^{*}$ & $0.005^{*}$ \\
\hline Employee & $1.382(0.720-2.653)$ & 0.332 & $1.42(1.13-3.201)$ & 0.12 \\
\hline \multicolumn{5}{|l|}{ Marital status } \\
\hline Married (ref) & 1.00 & & 1.00 & \\
\hline Single & $1.848(1.032-3.308)$ & $0.039^{*}$ & $1.411(0.593-4.125)$ & 0.219 \\
\hline \multicolumn{5}{|l|}{ Religion } \\
\hline Christian (ref) & 1.00 & & 1.00 & \\
\hline Non-Christian & $0.922(0.451-2.513)$ & $0.003^{*}$ & $0.726(0.067-2.503)$ & $0.011 *$ \\
\hline \multicolumn{5}{|l|}{ Work experience } \\
\hline Below 2 years (ref.) & 1.00 & & 1.00 & \\
\hline 2 to 4 years & $3.929(1.098-14.054)$ & $0.035^{*}$ & $11.727(0.998-137.824)$ & $0.05^{*}$ \\
\hline 5 to 7 years & $5.400(1.442-20.226)$ & $0.012^{*}$ & $13.159(1.135-152.596)$ & $0.039^{*}$ \\
\hline 8 to 10 years & $2.762(0.843-9.047)$ & 0.093 & 8.767 (0.843-91.170) & 0.069 \\
\hline 11 to 13 years & $1.821(0.427-7.761)$ & 0.417 & $4.827(0.366-63.721)$ & 0.232 \\
\hline Above 13 years & $1.134(0.400-3.213)$ & 0.813 & $2.571(0.274-24.117)$ & 0.408 \\
\hline \multicolumn{5}{|c|}{ Membership of workers association } \\
\hline Yes & $2.509(1.364-4.618)$ & $0.03^{*}$ & $4.20(1.56-7.75)$ & \\
\hline No (ref) & 1.00 & & 1.00 & 0.121 \\
\hline \multicolumn{5}{|c|}{ Exposure to electrical hazards } \\
\hline Yes & $1.8(1.102-3.05)$ & $0.045^{*}$ & $2.93(1.56-5.10)$ & $0.013^{*}$ \\
\hline No (ref) & 1.00 & & 1.00 & \\
\hline \multicolumn{5}{|c|}{ Suffering from occupational diseases } \\
\hline Yes & $2.2(1.25-4.256)$ & $0.001^{*}$ & $2.75(1.743-5.17)$ & $0.001^{*}$ \\
\hline No (ref.) & 1.00 & & 1.00 & \\
\hline
\end{tabular}

Italic values indicate significance of $p$ value

$\mathrm{Cl}$ confidence interval, $O R$ odd ratio, $A O R$ adjusted odd ratio

* p-value is significant at 0.05 or less 
to enroll in NHIS. Non-Christian participants were less likely to enroll in NHIS. These findings are useful for increasing the NHIS enrollment among informal sector workers in Ghana.

\section{Limitation}

As a result of the cross-sectional survey adopted, we were not able to establish causality between and among the study variables.

\begin{abstract}
Abbreviations
AIDS: Acquired Immunodeficiency Syndrome; HIV: Human Immunodeficiency Virus (HIV); NHIA: National Health Insurance Authority; NHIS: National Health Insurance Scheme; SSNIT: Social Security and National Insurance Trust; SPSS: Statistical Package for Social Sciences.
\end{abstract}

\section{Acknowledgements}

We acknowledge our study participants for providing the study data and the authors and publishers whose works were consulted.

\section{Authors' contributions}

DA conceived the study, DA and WA-D contributed to the design, DA and AAM collected the data, DA and WA-D analyzed the data and drafted the manuscript, DA and AAM reviewed the draft. DA, WA-D, and AAM addressed the review comments. All authors read and approved the final manuscript.

\section{Funding}

This research did not receive any specific grant from funding agencies in the public, commercial, or not-for-profit sectors.

\section{Data and material availability}

The datasets used and/or analyzed during the current study are available from the corresponding author on reasonable request.

\section{Ethics approval and consent to participate}

The Department of Planning, Kwame Nkrumah University of Science and Technology gave the approval to conduct the study. Informed written and verbal consents were obtained from the study participants before data were collected. Respondents were also assured of strict confidentiality and anonymity of the data they provided.

\section{Consent for publication}

Not applicable.

\section{Competing interests}

The authors declare that they have no competing interests.

Received: 29 March 2019 Accepted: 2 November 2019

Published online: 21 November 2019

\section{References}

1. Wedam EA, Sanyare FN. Health care financing and sustainability: a study of current conceptual dialectics in Ghana. World Dev Perspect. 2017;5:4755. https://doi.org/10.1016/j.wdp.2017.03.003.

2. Adisah-Atta I. Financing health care in Ghana: are Ghanaians willing to pay higher taxes for better health care? Findings from Afrobarometer. Soc Sci. 2017;6(3):1-19.
3. Nyonator F, Kutzin J. Health for some? The effects of user fees in volta region of Ghana. Health Policy Plan. 1999;14:329-41.

4. Mills A, Ataguba JE, Akazili J, Borghi J, Garshong B, Makawia S, Mtei G, Harris B, Macha J, Meheus F, Mclntyre D. Equity in financing and use of health care in Ghana, South Africa, and Tanzania: implications for paths to universal coverage. Lancet. 2012;380(9837):126-33.

5. Agyemang-Duah W, Peprah C, Peprah P. "Let's talk about money": how do poor older people finance their healthcare in rural Ghana? A qualitative study. Int J Equity Health. 2019;18(1):1-12.

6. Nsiah-Boateng E, Aikins M. Trends and characteristics of enrolment in the National Health Insurance Scheme in Ghana: a quantitative analysis of longitudinal data. Glob Health Res Policy. 2018;3(1):32.

7. NHIS. National Health Insurance Scheme, membership. 2018. http:// www.nhis.gov.gh/membership.aspx. Accessed 10 April 2018.

8. OXFAM International. Achieving a shared goal free universal healthcare in Ghana. 2011. http://www.anglicanhealth.org/Resources/PDF/AHN\%20res ources/Health\%20financing\%20and\%20Insurance/Oxfam\%20NHIS\%20 report.pdf. Accessed 13 July 2018.

9. National Health Insurance Scheme. Medicines list. 2018. https:// scholar.google.com/scholar?hl=en\&as_sdt=0\%2C5\&q=MEDIC INES+LIST\&btnG. Accessed 03 Jan 2018.

10. Rantanen J. Occupational health services for the informal sector. Afr Newsl Occup Health Saf. 2009;19(2):44-6.

11. Olaoye OJ, Odebiyl OC, Abimbola OT. Occupational hazards and injuries associated with fish processing in Nigeria. J Aquat Sci. 2015;3(1):1-5.

12. Kyei S, Owusu-Ansah A, Boadi-Kusi SB, Abbey DN, Abu EK. Occupational hazards correlates of ocular disorders in Ghanaian fisheries. Healthc LowResour Settings. 2016. https://doi.org/10.4081/hls.2016.5482.

13. Lattof SR. Health insurance and care-seeking behaviours of female migrants in Accra, Ghana. Health Policy Plan. 2018;33(4):505-15.

14. Aregbeshola BS, Khan SM. Predictors of enrolment in the National Health Insurance Scheme among women of reproductive age in Nigeria. Int J Health Policy Manag. 2018;7(11):1015.

15. Allcock SH, Young EH, Sandhu MS. Socio-demographic patterns of health insurance coverage in Namibia. Int J Equity Health. 2019;18(1):16.

16. Ghana Statistical Service. 2010 population and housing census: summary report of final results. Accra: Ghana Statistical Service; 2012.

17. Guilford JP, Fruchter B. Fundamental statistics in psychology and education. 5th ed. New York: McGraw-Hill Book Publishing Company; 1973.

18. Elfil M, Negida A. Sampling methods in clinical research; an educational review. Emergency. 2017;5(1):1-3.

19. Gujarati ND, Porter DC. Basic econometrics. 5th ed. New-York: McGrawHill Companies; 2009.

20. Kotoh AM, Aryeetey GC, Van der Geest S. Factors that influence enrolment and retention in Ghana' National Health Insurance Scheme. Int J Health Policy Manag. 2018;7(5):443-54.

21. Van Der Wielen N, Falkingham J, Channon AA. Determinants of National Health Insurance enrolment in Ghana across the life course: are the results consistent between surveys? Int J Equity Health. 2018;17(1):1-14.

22. Badu E, Agyei-Baffour P, Ofori Acheampong I, Preprah Opoku M, AddaiDonkor K. Households sociodemographic profile as predictors of health insurance uptake and service utilization: a cross-sectional study in a municipality of Ghana. Adv Public Health. 2018; 2018:1-13.

23. Tawiah EK. Factors influencing enrolment in the National Health Insurance Scheme among Slum Dwellers in Agbogbloshie (Masters dissertation, University of Ghana). 2015.

\section{Publisher's Note}

Springer Nature remains neutral with regard to jurisdictional claims in published maps and institutional affiliations. 